\title{
MS113.P06
}

\section{Crystal growing competition for high school students in Argentina}

Florencia Di Salvo ${ }^{1}$, Ricardo Baggio ${ }^{2}$, Eleonora Freire ${ }^{2}$, Valeria C. Fuertes ${ }^{3}$, Sebastián Klinke ${ }^{4}$, Griselda Polla ${ }^{2}$, Maricel Rodríguez ${ }^{1}$, Sebastián Suárez ${ }^{1}$, Diego Germán Lamas ${ }^{5}$

${ }^{1}$ DQIAQF/INQUIMAE-CONICET, FCEN, University Of Buenos Aires, Buenos Aires, Argentina, ${ }^{2}$ Gerencia de Investigación y Aplicaciones, Centro Atómico Constituyentes, Comisión Nacional de Energía Atómica, San Martin, Buenos Aires, Argentina, ${ }^{3} F C Q-U N C$, Córdoba, Argentina, ${ }^{4}$ Fundación Instituto Leloir, IIBBA -CONICET, Buenos Aires, Argentina, ${ }^{5}$ CONICET/Escuela de Ciencia y Tecnología-UNSAM, San Martín, Buenos Aires, Argentina E-mail: flor@qi.fcen.uba.ar

The first Crystal Growing Competition for high school students in Argentina was launched as part of the activities that the Argentinean Association of Crystallography (AACr) developed to celebrate the International Year of Crystallography 2014 (IYCr2014). Due to the great success, and high number of students and teachers participating, new editions have taken place the following years (2nd and 3rd competitions in 2015 and 2016, respectively and the current edition in 2017). The activity is sponsored by the IUCr, CONICET (Argentinean Science Council), the Argentinean Ministry of Science, Innovation and Technology and State Universities such as, UNSAM (2014-2017), UNC (2016) and UBA (2015 and 2017 ).

Based on IUCr suggestion [1] and successful previous experiences in other countries [2], we planned the first program and guidelines of the activity in 2014. The information of the competition is available in our website and Facebook page, and includes: guidelines, crystal growing experiences, previous editions winner's projects and useful links related to crystal growing and crystallography [3].

The activity takes place from March to November and it is mainly divided in three parts. During Part I (March to June) we offer training courses to teachers. It is a five hours course covering the topics: introduction to crystalline solids, basis of Xray diffraction and crystallisation, crystal growing experiences and details of the Argentinean Competition. Approximately 40 courses are delivered every year covering all the areas of the country and with the assistance of about 1000 participants. During Part II the students develop the crystal growing experiences using exclusively the allowed substances (sugar, sodium chloride, copper sulphate, borax and potassium alum) and then, create a video or a report to show their work to the evaluation committee. Deadline is about first days of September. After evaluation, winners and honorary diplomas are announced. Around 350 to 500 projects have participated of the competition every year. Part III comprehends the Final of the Competition; this event takes place every year during one day of the first week of November. In 2014 it was held in Mar del Plata, Province of Buenos Aires, in 2015 in the University of Buenos Aires, City of Buenos Aires and in 2016 in National University of Cordoba, City of Córdoba. In this wonderful and emotive event the winners (15 groups approximately) are invited to present their projects (crystals) and a poster. Honorary diploma projects are also invited to participate of this event and show their crystals. The day ends with the awards ceremony of the Crystal Growing Competition.

Every year, everyone participating of the Argentinean contest has a chance to participate in the International Crystal Growing Competition. Argentina had excellent results in every edition and what is more important, it was always the country with the higher number of submitted projects.

Through this exciting, funny and hands-on scientific experience, crystallography and other related scientific fields are promoted along the high school community across the country being also, a way to encourage youth to continue exploring science and developing their scientific skills.

[1] http://www.iycr2014.org/participate/crystal-growing-competition-2017

[2] http://www.lec.csic.es/concurso/

[3] http://www.cristalografia.com.ar/index.php/concurso-cristales-2016

Keywords: IYCr legacy, crystal growing competition, develop of scientific skills in high school students 